\title{
PENGEMBANGAN SISTEM INFORMASI REKAM MEDIS UNTUK DINAS KABUPATEN GROBOGAN
}

\author{
Purnaresa Yuliartanto ${ }^{1)}$, Adian Fatchur Rochim ${ }^{2)}$, Ike Pertiwi Windasari ${ }^{2)}$ Program Studi Sistem \\ Komputer, Fakultas Teknik, Universitas Diponegoro, Jln. Prof. Sudharto, Tembalang, Semarang, \\ Indonesia email : purnaresa@live.com
}

Abstract - Health services include the recording of the patient's medical record. Medical records were used to aid the treatment process. The number of medical records continues to grow proportional to the number of patients. Tens of thousands of sheets of paper used to record medical record requires effort, time and place great. The amount of effort will continue to grow each day. Search one sheet of medical records among a set of storage shelves requires considerable time and risk data is not found. The risk of error in the search and storing will increase every day.

The development of technology allows the implementation of technology in the process of record-keeping. Changes in the form of digital medical records will reduce the need of a previous process. Labor, time and place required by the help of information systems will be reduced significantly. Storage process data stored in the cloud will provide more value for the system as a patient's medical records from a health center can be accessed from other health centers. The development of this system will reduce the risk of inappropriate storage and retrieval of medical records.

Grobogan Health Department that oversees health center in Grobogan are office that are ready to migrate business processes into the digital age. Development of medical record information system for the health center expected to improve the quality of service of health centers, especially in health care.

Key Word : information system, web apps, cloud computing, medical record

\section{PENDAHULUAN}

Untuk menunjang pelayanan kesehatan yang diberikan puskesmas, setiap tindakan dalam upaya pengobatan dicatat dalam data rekam medis pasien. Data rekam medis tersebut berisi anemnesis atau hasil pemeriksaan, dan obat yang diberikan. Dalam satu hari jumlah pengunjung puskesmas bisa mencapai 100 orang yang berarti dalam satu tahun akan ada ribuan data rekam medis. Banyaknya jumlah rekam medis yang harus dikelola puskesmas menimbulkan permasalahan karena membutuhkan tenaga, waktu dan tempat yang besar.

Metode pencatatan rekam medis pada kertas merupakan salah satu faktor utama besarnya kebutuhan yang harus dipenuhi. Upaya pencarian satu lembar rekam medis dari seluruh rak kertas membutuhkan waktu yang banyak. Pengembangan sistem informasi sebagai sarana pencatatan rekam medis digital dapat mengurangi tenaga yang dibutuhkan secara signifikan, mempercepat pengolahan rekam medis dan mengurangi tempat yang dialokasikan untuk menyimpan ribuan kertas rekam medis.

Unit puskesmas pada suatu wilayah melakukan aktifitasnya dibawah tanggung jawab Dinas Kesehatan setempat. Dinas Kesehatan Grobogan merupakan instansi yang sedang mempersiapkan diri untuk migrasi ke era digital dalam proses bisnisnya. Permasalahan rekam medis pada puskesmas yang dipandang belum memiliki solusi tepat diharapkan dapat diselesaikan dengan teknologi rekam medis online.

Tujuan dari tugas akhir ini adalah Menghasilkan sistem informasi yang berhasil memenuhi kebutuhan puskesmas dalam mengelola rekam medis dan memiliki kehandalan untuk digunakan di lapangan.

Adapun pembatasan masalah pada makalah ini adalah sebagai berikut :

1) Sistem berupa aplikasi berbasis web yang diakses pengguna dengan web browser.

2) Kode perangkat lunak ditulis menggunakan bahasa pemrograman $\mathrm{C} \#$ dengan kerangka kerja ASP.NET MVC.

3) Basis data dijalankan dengan SQL Server.

4) Fitur utama sistem adalah mengelola data pasien, data riwayat pasien, dan data pemakaian obat.

5) Lingkup kerja sistem adalah Unit Puskesmas Godong 1 Dinas Kesehatan Grobogan.

\section{DASAR TEORI}

A. Sistem Informasi

Sistem adalah entitas atau satuan yang terdiri dari dua atau lebih komponen atau subsistem (sistem yang lebih kecil) yang saling terhubung dan terkait untuk mencapai suatu tujuan. Informasi merupakan fakta yang memiliki arti sehingga memungkinkan untuk dimanfaatkan. Sedangkan semua fakta tersebut yang tercatat, terekam atau terdokumentasikan disebut data.

Sistem Informasi adalah cara yang terorganisir untuk mengumpulkan, memasukan dan memproses data yang menyimpannya, mengelola, mengontrol dan melaporkanya sehingga dapat mendukung perusahaan atau organisasi mencapai tujuan (Tantra, 2012).

\section{B. Sistem Basis Data}

Sistem Basis Data merupakan sistem yang terdiri atas kumpulan tabel data yang saling berhubungan (dalam sebuah basis data di sebuah sistem komputer) dan sekumpulan program (yang biasa disebut Data Base Management System) yang memungkinkan beberapa pemakai dan/atau program lain untuk mengakses dan memanipulasi tabel data tersebut. Penjelasan tersebut 
merupakan penjelasan yang dilansir dari buku Basis

Data (Fathansyah, 2012).

\section{ASP.NET MVC}

ASP.NET MVC adalah kerangka kerja pengembangan Web dari Microsoft yang menggunakan arsitektur MVC. ASP.NET MVC merupakan ide dan teknik paling terbaru dalam pengembangan Agile dan merupakan kerangka kerja terbaik dari platform ASP.NET (Freeman, 2013). Kerangka kerja ini merupakan alternatif lengkap sebagai pengganti ASP.NET Web Forms. Keuntungan dari kerangka kerja ini adalah;

1) Arsitektur MVC yang merupakan standart pengembangan $W e b$ dengan konsep pembagian area konstentrasi (model-viewcontroller)

2) Ekstensif komponen yang merupakan ekosistem ASP.NET dimana komponen dapat diganti atau diturunkan sesuai kebutuhan. Pada umumnya seluruh komponen default ASP.NET MVC sudah mencukupi untuk keperluan pengembangan $\mathrm{Web}$.

3) Modern API yang selalu didukung Microsoft .NET. Memberikan keuntungan bagi pengembang untuk terus dapat mengembangan $\mathrm{Web}$ yang memiliki teknologi terbaru. Iterasi terakhir .NET 4.5.1 memberikan fasilitas LINQ pada ASP.NET MVC.

D. SQL Server

SQL Server adalah hasil kerjasama antara

Microsoft dan Sybase untuk memproduksi sebuah perangkat lunak penyimpanan data (basis data) yang bekerja pada sistem operasi OS/2. Untuk masa depan, SQL Server sebagai piranti penyimpanan data akan lebih digiatkan dengan fokus pada kebutuhan korporasi besar agar produk tersebut dapat bersaing dengan produk sejenis yang dimiliki oleh IBM maupun Oracle. Penjelasan tersebut dilansir dari buku Basis Data (Fathansyah, 2012). Sekarang SQL Server mempunyai versi terakhir SQL Server 2012. SQL Server 2012 memiliki beberapa edisi yang memungkinkan untuk digunakan pada bermacam sekmen pasar.

\section{E. Visual Studio}

Visual Studio adalah Integrated Development Environment (IDE) dari Microsoft yang digunakan untuk membuat, menjalankan dan memperbaiki program (aplikasi). Visual Studio dapat digunakan untuk membuat aplikasi dengan berbagai bahasa yang didukung .Net seperti $\mathrm{C}++, \mathrm{C} \#$ dan VB. IDE ini sangat kuat dan memiliki tool yang canggih untuk membuat aplikasi bisnis. Visual Studio yang terakhir adalah Visual Studio 2013 (Moore, 2010).
F. UML

UML muncul karena adanya kebutuhan pemodelan visual untuk menspesifikasikan, menggambarkan, membangun, dan dokumentasi dari sistem perangkat lunak. UML merupakan bahasa visual untuk pemodelan dan komunikasi mengenai sebuah sistem dengan menggunakan diagram dan teks-teks pendukung (Hamilton \& Miles, 2006).

UML hanya berfungsi untuk melakukan pemodelan. Jadi penggunaan UML tidak terbatas pada metodologi tertentu, meskipun kenyataannya UML paling banyak digunakan pada metodologi berorientasi objek. Mengacu pada spesifikasi pada UML Supersctructure (OMG, 2011) UML 2.2 terdiri dari 14 macam diagram yang dikelompokkan dalam 2 kategori.

\section{PERANCANGAN SISTEM}

A. Analisis Kebutuhan

1) Prespektif Produk Akhir

Produk yang berupa sistem informasi dapat digunakan oleh puskesmas dalam melakukan pelayanan. Rekam medis pasien disimpan dalam bentuk data digital didalam sistem.

2) Fungsi Produk

Produk dapat menyimpan data pasien untuk digunakan berulang kali dalam setiap pelayanan. Data rekam medis pasien dapat disimpan kedalam sistem. Seluruh kegiatan dicatat sistem untuk menghasilkan laporan.

3) Kelompok Pengguna

Pengguna yang menggunakan sistem ini terdiri dari 3 jenis, yaitu: pengguna superadmin, pengguna admin, dan pengguna petugas. Ketiga pengguna tersebut memiliki aktivitas yang berbeda dalam menggunakan sistem.

B. Desain Sistem

1) Arsitektur Sistem

Sistem berupa aplikasi berbasis web. Aplikasi berjalan pada web server. Pengguna mengakses aplikasi menggunakan web browser. Gambar 1 menunjukan arsitektur sistem.

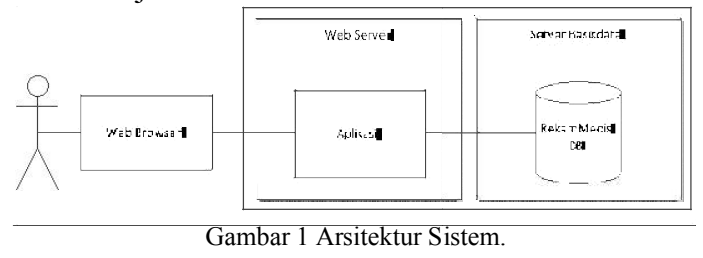

2) Arsitektur Aplikasi

Arsitektur aplikasi menunjukan komponen yang digunakan dalam membangun aplikasi. Gambar 2 menunjukan arsitektur aplikasi yang dibangun.

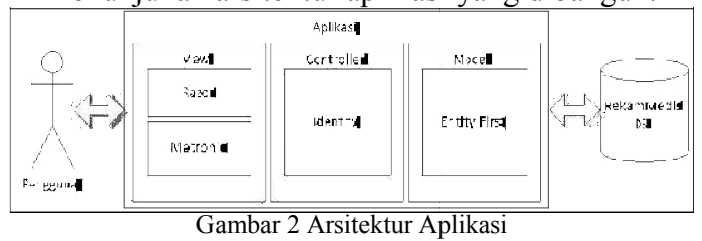


3) Diagram Aktivitas

Diagram aktivitas menjelaskan bagaimana proses bisnis yang dilakukan pengguna. Gambar 3 menunjukan diagram aktivitas sistem.

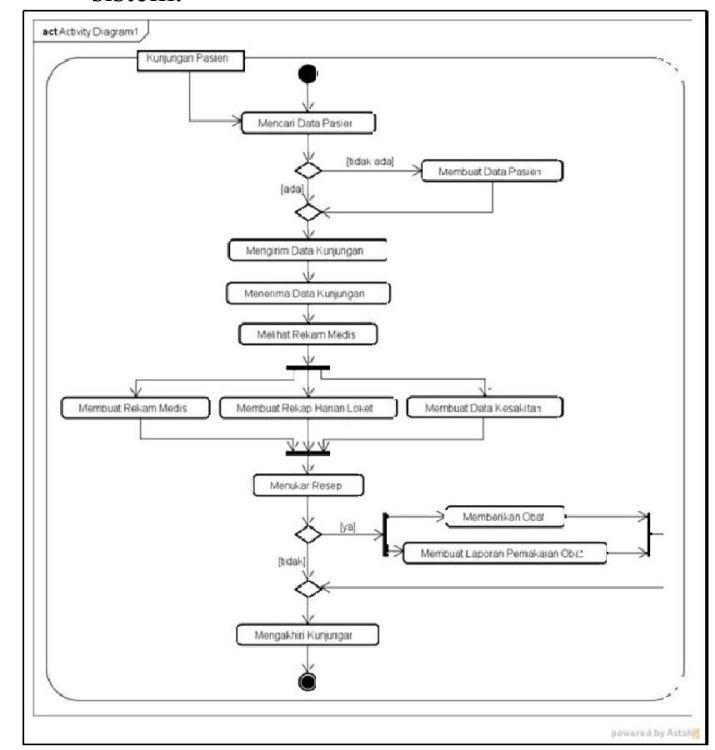

Gambar 3 Diagram Aktivitas sistem.

4) Diagram Use Case

Diagram use case menunjukan skenario yang dilakukan oleh pengguna. Gambar 4 menunjukan diagram use case.

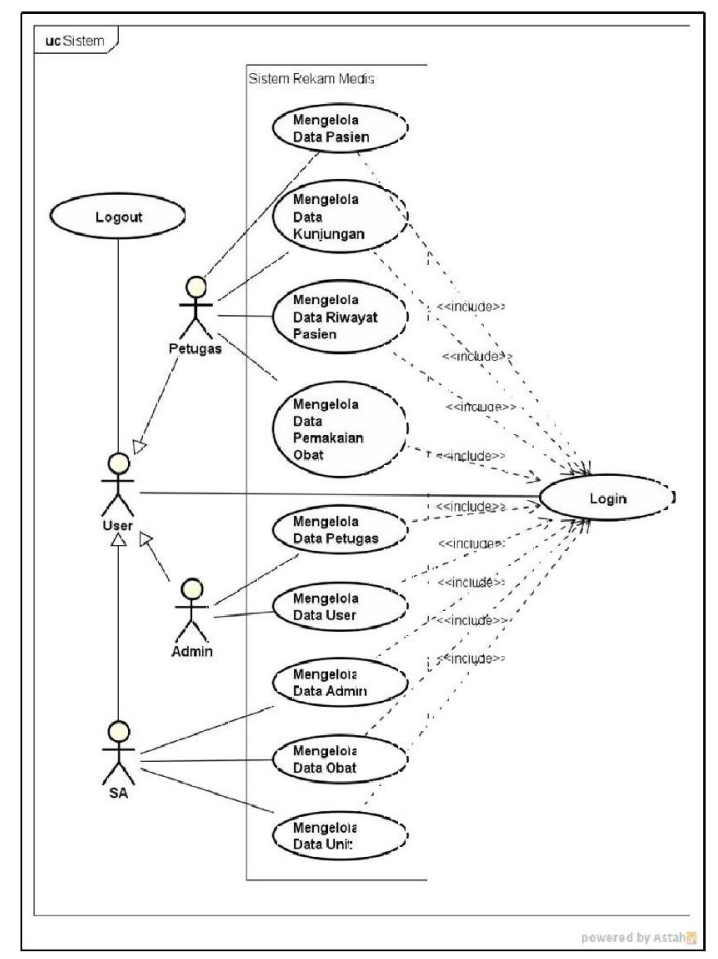

Gambar 4 Diagram use case sistem.

\section{5) Diagram Sequence}

Diagram sequence dapat mengambarkan bagaimana komponen dalam sistem berinteraksi. Salah satu use case digunakan untuk menunjukan interaksi tersebut. Gambar 5 menunjukan salah satu use case yang digunakan sebagai acuan diagram sequence.

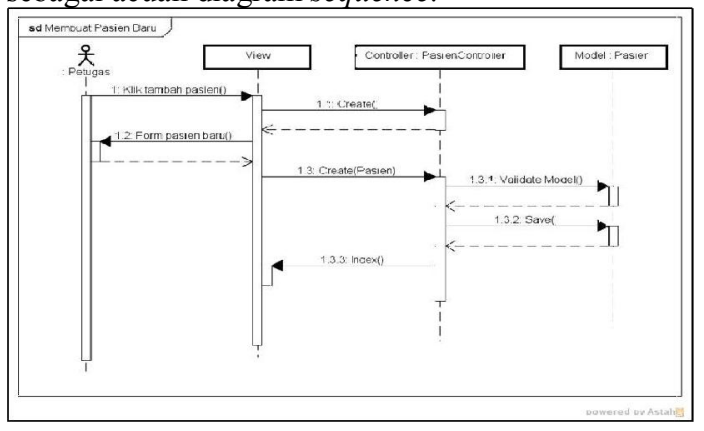

Gambar 5 Diagram use case menambah pasien

6) Diagram Kelas

Diagram kelas menunjukan struktur aplikasi yang dikembangkan. Gambar 6 menunjukan diagram kelas sistem.

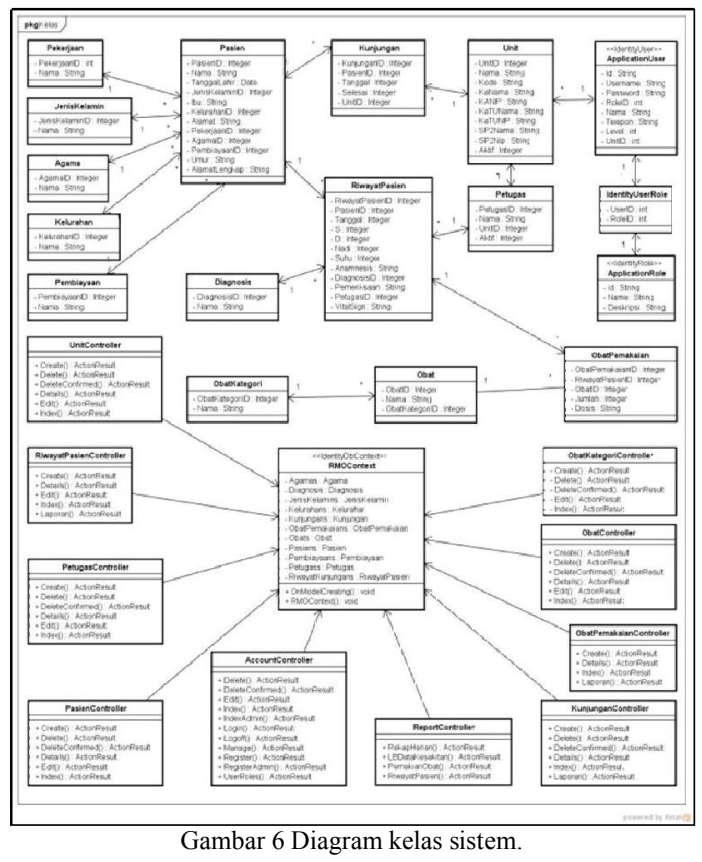

7) Desain Antarmuka

Desain sistem menggunakan template Metronic. Antarmuka yang dipakai adalah tabel data, form data, navigasi, login. Gambar 7 menunjukan tabel data yang telah dimasukan dalam container navigasi.

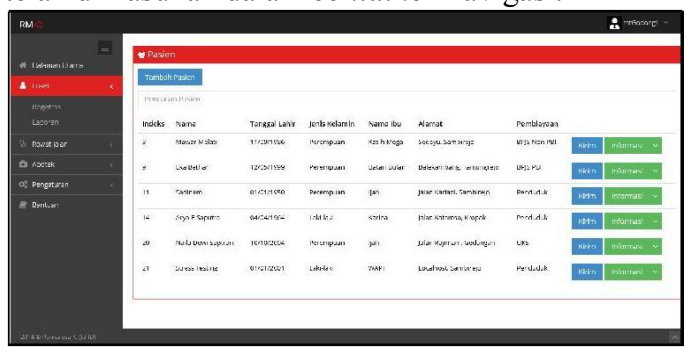




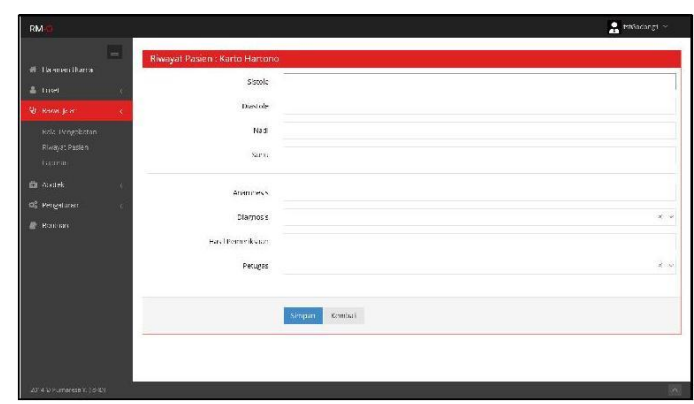

Gambar 7 Desain antarmuka sistem

\section{PENGUJIAN SISTEM}

A. Pengujian Unit

Pengujian unit dilakukan untuk mengetahui apakah masing masing fungsi didalam sistem dapat berfungsi dengan benar. Pengujian dilakukan dengan teknik kotak hitam. Teknik tersebut menganalisis hasil keluaran ketika sebuah fungsi dijalankan. Gambar 8 menunjukan halaman login sistem.

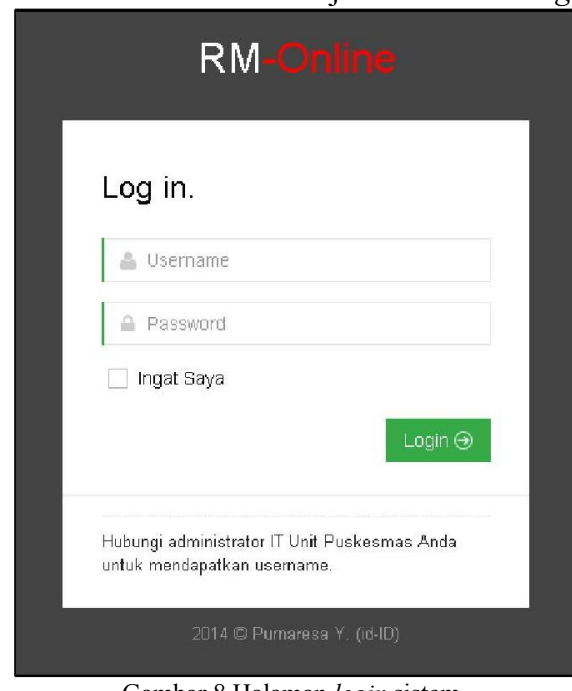

Gambar 8 Halaman login sistem.

Pengguna dapat menjalankan fungsi lain setelah berhasil login. Gambar 9 menunjukan petugas menambah pasien baru.

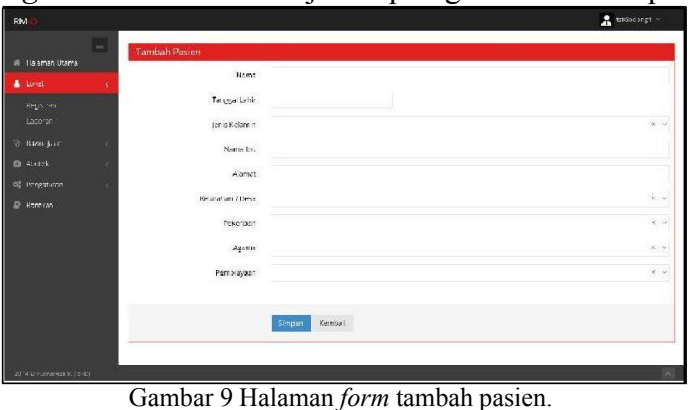

Petugas membuka form riwayat pasien untuk menyimpan data pelayanan. Gambar 10 menunjukan form data riwayat pasien

Gambar 10 Halaman form riwayat pasien

Fungsi riwayat kesehatan pasien dapat dipanggil untuk membuat laporan yang berasal dari data yang telah disimpan. Gambar 11 menunjukan dokumen riwayat kesehatan pasien.

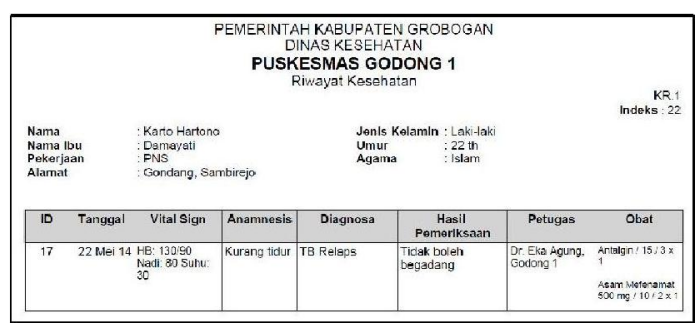

Gambar 11 Dokumen riwayat kesehatan pasien.

Funggsi laporan data kesakitan digunakan untuk menampilkan laporan berdasarkan diagnosis yang diberikan Gambar 12 menunjukan dokumen laporan data kesakitan.

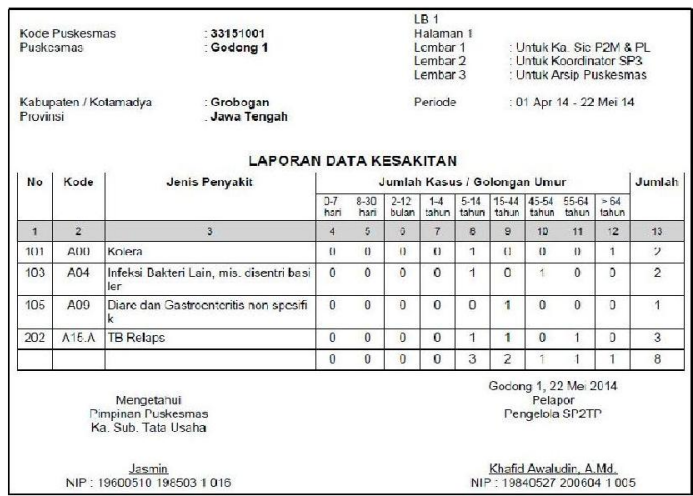

Gambar 12 Dokumen laporan data kesakitan.

Semua fungsi diuji untuk mencari kesalahan sistem. Tabel 1 menunjukan analisis pengujian unit yang telah dikategorikan.

Tabel 1 Analisis pengujian unit.

\begin{tabular}{|c|c|c|c|}
\hline Pengujian & Tindakan & Harapan & Analisis \\
\hline Login & $\begin{array}{l}\text { Memasukan } \\
\text { username dan } \\
\text { password }\end{array}$ & $\begin{array}{l}\text { Berhasil } \\
\text { masuk sistem }\end{array}$ & Berhasil \\
\hline $\begin{array}{l}\text { Mengelola Data } \\
\text { Pasien }\end{array}$ & $\begin{array}{l}\text { Membuat, } \\
\text { melihat, } \\
\text { mengubah } \\
\text { menghapus }\end{array}$ & $\begin{array}{l}\text { Data Pasien } \\
\text { bisa diolah }\end{array}$ & berhasil \\
\hline $\begin{array}{l}\text { Mengelola Data } \\
\text { Kunjungan }\end{array}$ & $\begin{array}{l}\text { Membuat, } \\
\text { melihat, } \\
\text { menghapus }\end{array}$ & $\begin{array}{l}\text { Data } \\
\text { Kunjungan } \\
\text { bisa diolah }\end{array}$ & berhasil \\
\hline Mengelola data & Membuat, & $\begin{array}{ll}\text { Data } & \text { riwayat } \\
\end{array}$ & berhasil \\
\hline riwayat pasien & $\begin{array}{l}\text { melihat, } \\
\text { mengubah } \\
\text { menghapus }\end{array}$ & $\begin{array}{l}\text { pasien bisa } \\
\text { diolah }\end{array}$ & \\
\hline $\begin{array}{l}\text { Mengelola Data } \\
\text { Pemakaian Obat }\end{array}$ & $\begin{array}{l}\text { Membuat, } \\
\text { melihat, } \\
\text { menghapus }\end{array}$ & $\begin{array}{l}\text { Data } \\
\text { pemakaian } \\
\text { obat bisa } \\
\text { diolah } \\
\end{array}$ & berhasil \\
\hline $\begin{array}{l}\text { Mengelola Data } \\
\text { Petugas }\end{array}$ & $\begin{array}{l}\text { Membuat, } \\
\text { melihat, } \\
\text { mengubah } \\
\text { menghapus }\end{array}$ & $\begin{array}{l}\text { Data petugas } \\
\text { bisa diolah }\end{array}$ & berhasil \\
\hline $\begin{array}{l}\text { Mengelola Data } \\
\text { User }\end{array}$ & $\begin{array}{l}\text { Membuat, } \\
\text { melihat, } \\
\text { mengubah } \\
\text { menghapus }\end{array}$ & $\begin{array}{l}\text { Data user bisa } \\
\text { diolah }\end{array}$ & berhasil \\
\hline $\begin{array}{l}\text { Mengelola Data } \\
\text { Admin }\end{array}$ & $\begin{array}{l}\text { Membuat, } \\
\text { melihat, } \\
\text { mengubah } \\
\text { menghapus }\end{array}$ & $\begin{array}{l}\text { Data admin } \\
\text { bisa diolah }\end{array}$ & berhasil \\
\hline $\begin{array}{l}\text { Mengelola Data } \\
\text { Obat }\end{array}$ & $\begin{array}{l}\text { Membuat, } \\
\text { melihat, } \\
\text { mengubah } \\
\text { menghapus }\end{array}$ & $\begin{array}{l}\text { Data obat bisa } \\
\text { dikelola }\end{array}$ & berhasil \\
\hline Mengelola Data & Membuat, & Data unit bisa & berhasil \\
\hline
\end{tabular}




\begin{tabular}{|l|l|l|l|} 
Unit & $\begin{array}{l}\text { melihat, } \\
\text { mengubah } \\
\text { menghapus }\end{array}$ & dikelola & \\
\hline
\end{tabular}

B. Pengujian Integrasi

Pengujian integrasi dilakukan untuk mengetahui apakah fungsi yang bekerja dalam sistem mampu saling terhubung untuk menjalankan skenario pekerjaan yang dilakukan pengguna. Tabel 2 menunjukan analisis pengujian integrasi.

Tabel 2 Analisis pengujian integrasi

\begin{tabular}{|l|l|l|}
\hline Skenario & Fungsi Terkait & Analisis \\
\hline $\begin{array}{l}\text { Pengguna Admin } \\
\text { 2 pedong 1 memiliki }\end{array}$ & $\begin{array}{l}\text { Login, membuat pengguna } \\
\text { admin, membuat pengguna } \\
\text { petugas, menentukan } \\
\text { pengguna role. }\end{array}$ & Berhasil \\
\hline $\begin{array}{l}\text { Pengguna Admin } \\
\text { Wirosari 1 memiliki }\end{array}$ & $\begin{array}{l}\text { Login, membuat pengguna } \\
\text { admin, membuat pengguna } \\
\text { petugas, menentukan } \\
\text { pengguna role. }\end{array}$ & Berhasil \\
\hline $\begin{array}{l}\text { Pasien baru } \\
\text { melakukan } \\
\text { kunjungan dilayani } \\
\text { hingga kunjungan } \\
\begin{array}{l}\text { Selesai } \\
\text { menggunakan }\end{array}\end{array}$ & $\begin{array}{l}\text { Login, membuat data pasien } \\
\text { baru, membuat kunjungan } \\
\text { baru, membaca kunjungan, } \\
\text { membuat riwayat pasien } \\
\text { baru, membaca riwayat } \\
\text { pasien, membuat pemakaian } \\
\text { obat }\end{array}$ & Berhasil \\
\hline $\begin{array}{l}\text { Pasien lama } \\
\text { berkunjung kembali } \\
\text { dilayani dengan } \\
\text { data yang sudah ada } \\
\text { didalam sistem }\end{array}$ & $\begin{array}{l}\text { Login, mencari data pasien, } \\
\text { membuat kunjungan baru, } \\
\text { membaca kunjungan, } \\
\text { membuat riwayat pasien } \\
\text { baru, membaca riwayat } \\
\text { pasien, membuat pemakaian } \\
\text { obat }\end{array}$ & Berhasil \\
$\begin{array}{l}\text { Laporan dapat } \\
\text { dihasilkan dengan } \\
\text { data yang } \\
\text { pidapatkan dari }\end{array}$ & $\begin{array}{l}\text { Login, membuat kunjungan } \\
\text { baru, membuat riwayat } \\
\text { pasien baru, membuat } \\
\text { pemakaian obat baru }\end{array}$ & Berhasil \\
\end{tabular}

Semua tahap pengujian yang dilakukan menunjukan sistem memiliki fungsi yang bekerja dengan benar dengan keluaran data yang valid. Pengembangan sistem dapat dikatakan selesai

\section{KESIMPULAN DAN SARAN}

A. Kesimpulan

Selama pengembangan sistem informasi ini

terdapat beberapa hal yang bisa diamati dan dianalisis. Proses yang tertulis pada laporan ini memberikan kesimpulan;

1. Setiap pasien yang terdaftar memiliki nomor PasienID berupa nomor yang selalu digunakan dalam pengolahan apapun.

2. Antrian pasien yang berkunjung didapatkan dari data kunjungan pada hari itu menggunakan kolom Tanggal.

3. Penyimpanan Riwayat Pasien membutuhkan data petugas yang merupakan foreign key dari tabel Petugas. Apoteker menyimpan data pemakaian obat dengan menggunakan RiwayatPasienID.

4. Semua aktifitas dalam sistem dibedakan dengan UnitID pada user login.

5. Laporan yang dihasilkan sistem memiliki format PDF.
6. Sistem hanya dapat digunakan dengan fungsi otorisasi

7. yang didukung .NET Identity

8. Basis data berada di platform Azure yang memiliki ukuran dinamis sehingga ukuran basis data dapat diatur menyesuaikan kebutuhan.

\section{B. Saran}

1. Sistem informasi memiliki banyak ruang untuk dikembangkan kembali sesuai kebutuhan pada masa depan.

2. Fitur reset password belum bisa di implementasikan dengan framework Identity versi 1 sehingga harus diperhatikan karena user yang kehilangan password tidak bisa mendapatkan password tanpa bantuan admin.

\section{DAFTAR PUSTAKA}

Dewson, R. (2012). Beginning SQL Server 2012 for Developers. New York: Apress.

Earp, R., \& Bagui, S. (2003). Database Design Using EntityRelationship Diagrams. Library (Vol. 2003, p. 371). Florida: Auerbach.

Fathansyah. (2012). Basis Data. Bandung: Informatika. Freeman, A. (2013). Pro ASP.NET MVC 5. New York: Apress.

Hales, W. (2013). HTML5 and JavaScript Web Apps. California: O'Reilly Media, Inc.

Hamilton, B. K., \& Miles, R. (2006). Learning UML 2.0. Polymer Contents (Vol. 23, pp. 865-923). California: O'Reilly Media, Inc.

Hatta, G. R. (2008). Pedoman Manajemen Informasi Kesehatan Di Sarana Pelayanan Kesehatan. Jakarta: Universitas Indonesia.

Kameswara, A. D. (2012). Perancangan Sistem Administrasi Dan Rekam Medis Klinik Gigi. Universitas Diponegoro.

Moore, A. (2010). Visual Studio 2010 All-in-One For Dummies. Building (p. 916). New Jersey: Wiley Publishing, Inc.

Murdani, E. (2007). Pengembangan Sistem Informasi Rekam Medis Rawat Jalan Untuk Mendukung Evaluasi Pelayanan Di RSU Bina Kasih Ambarawa. Universitas Diponegoro.

Oktavian, D. P. (2010). Menjadi Programmer Jempolan Menggunakan PHP. Yogyakarta: Mediakom.

OMG. (2011). UML 2.4.1-Infrastructure Specification. Available on: http://www. omg. org/spec/UML/2.1. Massachusetts.

Pilgrim, M. (2010). HTML5: Up and Running. Library

Puspitasari, Y., Purnama, B. E., \& Sukadi. (2013). Sistem Informasi Rekam Medis Pasien Rawat Jalan Dan Observasi Pada Puskesmas Pringkuku Kabupaten Pacitan. IJNS - Indonesian Journal on Networking and Security, 2. 
Rasheed, F. (2006). C\# School. Fungeriola: Synchron Data.

Rosa A.S, \& M. Shalahuddin. (2011). Modul Pembelajaran Rekayasa Perangkat Lunak. Bandung: Modula.

Rusli, A., Asri Rasad, Enizar, Irdjiati, I., Subekti, I., Suprapta, I. P., ... Akbar, S. M. S. (2006).

Manual Rekam Medis. Jakarta.

Sidik, B. (2010). Pemrograman Grafik dengan Java. Bandung: Informatika.

(p. 205). California: O’Reilly Media, Inc. Pressman, R. S. (2012). Rekayasa Perangkat Lunak.

Tantra, R. (2012). Manajemen Proyek Sistem Informasi. Yogyakarta: ANDI.

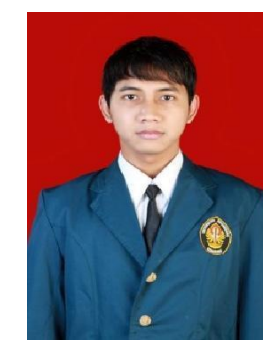

BIODATA

Purnaresa Yuliartanto lahir di Grobogan 15 Juli 1991. Menempuh pendidikan formal di SMK N 7 Semarang dengan jurusan Teknik Komputer dan Jaringan. Sekarang sedang dalam proses menyelesaikan pendidikan Strata Satu di Program Studi Sistem Komputer, Universitas Diponegoro, Semarang,

Indonesia Angkatan Tahun 2010 